\title{
From admiration of the problem to action: Addressing the limited success in vocational rehabilitation of persons from diverse racial and cultural backgrounds
}

\author{
Timothy N. Tansey ${ }^{\mathrm{a}, *}$, Alo Dutta ${ }^{\mathrm{b}}$, Madan Kundu ${ }^{\mathrm{b}}$ and Fong Chan ${ }^{\mathrm{a}}$ \\ ${ }^{a}$ University of Wisconsin-Madison, Madison, WI, USA \\ ${ }^{\mathrm{b}}$ Southern University and A\&M College, Baton Rouge, LA, USA
}

Revised/Accepted June 2016

Keywords: Disability, poverty, diversity, minority

The authors of the articles published in this issue of Journal of Vocational Rehabilitation (Issue 45[2]) and corresponding editorial by Dr. Paul Wehman provide ample support for the following assertions: 1) work is central to the health and well-being of people with or without disabilities; 2) people with disabilities are significantly less likely to be working than people without disabilities; 3) people from diverse racial and cultural backgrounds, with disabilities or without disabilities, experience additional barriers in obtaining and retaining employment; and 4) people with disabilities from diverse racial and cultural backgrounds receiving services from state vocational rehabilitation (VR) agencies lag behind their non-Hispanic white counterparts in terms of employment outcomes and employment quality. Work, beyond the financial benefits, promotes societal participation through opportunities for social interaction and support while also offering protective factors that promote mental well-being, physical health, and community participation (Chiu et al., 2015; Neff, 1986; Strauser, 2014).

*Address for correspondence: Timothy N. Tansey, 1000 Bascom Mall, Madison, WI 53706, USA. Tel.: +1 608265 8991; E-mail: tntansey@wisc.edu.
In the United States, the labor force participation rate of $20.5 \%$ for people with disabilities is significantly lower than the $68.4 \%$ rate for people without disabilities (U.S. Department of Labor, 2016). The unemployment and underemployment of people with disabilities limits full community inclusion and participation, stalls upward mobility, and negatively affects their health-related quality of life (U.S. Senate Committee on Health, Education, Labor and Pensions [SCHELP], 2012). People from diverse racial and cultural backgrounds, when compared to non-Hispanic whites, experience greater educational barriers and fewer opportunities for developing the vocational skills and behavior that are necessary for obtaining and retaining employment. Even when controlling for the impact of education, people from diverse backgrounds are less likely to obtain employment, and ultimately, are paid on average $37 \%$ less for their work (Yin, Shaewitz, \& Megra, 2014). This large disability wage gap is consistent with the gender and race discrimination in the job market (Fryer, Pager, \& Spenkuch, 2011). The fact this group is less likely to be accepted for VR services in comparison to their non-Hispanic white counterparts complicates the 
employment outlook even further (Chan, et al., 2005). Finally, although not specifically addressed by the articles in this special issue, the effects of generational poverty and of living in marginalized communities cannot be overlooked. People with disabilities are almost twice as likely to be living in poverty as people without disabilities (Erickson, Lee, \& von Schrader, 2012; Institute on Disability, 2016). The consequences of living in poverty include low academic success, food insecurity, increased odds of living in an unsafe neighborhood, substandard health care resulting in decreased physical health, increased stress and depression, and, if employed, a greater chance of working in jobs associated with higher risk for injury and death (Committee on Health, Education, Labor, and Pension, 2014; Dutta \& Kundu, 2013; Gomez \& Haymann, 2009; Rogers, et al., 2011).

The above is a summary of the challenges experienced by people with disabilities from diverse racial and ethnic backgrounds. Articles in this special issue make an important contribution by shedding greater light on the challenges experienced by this population. However, research is needed that demonstrates methods to address the multiple discrimination related to the intersection between disability, gender, race and poverty, and increase the employment outlook for these individuals. In a recent presentation, Dr. Wehman (2016) clarified limitations in existing research and practice by providing the following statement (attributed to Dr. David Test):

Are we ready to develop meaningful interventions that empirically prove what works for better employment outcomes or will we continue to Admire the Problem?

As researchers, educators, and practitioners, we have become experts in identifying variations and limitations in VR service provision and the subsequent impact on employment, inclusion, health, and quality of life of people with disabilities. However, as the statement above suggests, efforts related to identification and admiration are less than comforting for people with multiple stigmatized identities, many of whom live in disadvantaged communities. These communities have been marginalized to the point of being: (a) less likely to apply for VR services as a function of being less likely to be found eligible for services; (b) less likely to engage in services due to minimization of their role in the rehabilitation process; and (c), as a result, are more likely to be closed from services without obtaining employment.
The state-federal VR program has achieved marked success in assisting people with disabilities to obtain and retain employment. Rehabilitation counselors working in these agencies are highly trained professionals. However, the accreditation standards for programs in rehabilitation counselor education are focused on generalist training for serving the broad needs of persons with disabilities across different service provision settings (Tansey \& Smart, 2004; Tansey, 2008). As a result, rehabilitation counselors, and subsequently state VR agencies, are limited in their ability to serve individuals with multiple stigmatized identities living in disadvantaged communities. Further, there is a scarcity of research that supports evidenced-based interventions for individuals with disabilities from diverse racial and ethnic backgrounds from these communities.

The Rehabilitation Services Administration (RSA), recognizing the barriers experienced by people with disabilities living in these marginalized communities where poverty and unemployment are epidemic, solicited proposals for the Vocational Rehabilitation Technical Assistance Center for Targeted Communities (VRTAC-TC). Historically, technical assistance centers have focused on providing training and support to state VR agencies in interventions and programs intended to promote employment of persons with disabilities and improve efficiency of VR service provision. Unlike the technical assistance centers either previously supported by RSA or those created in the last two years, the VRTAC-TC was created to demonstrate, train, and support counselors in developing multicultural competence, to engage individuals with multiple stigmatized identities living in marginalized communities in VR, and to improve their employment and quality of life outcomes. The VRTAC-TC, led by Southern University and A\&M College, with its Project E3: Educate, Empower, and Employ, is currently developing a system of interventions for 12 distinct Targeted Communities (TC) across the nation. These TC projects, designed and implemented by Project E3 personnel with assistance from state VR agencies and community partners, is intended to apply emerging, promising, and evidence-based VR practices in these TCs to support the identification, recruitment, and engagement of persons with disabilities in state VR services. The project will strive to engage community stakeholders such as employers, schools, correction institutions, social services providers and community rehabilitation providers to address systemic obstacles such as 
homelessness, hunger, safety concerns, interpersonal and family issues, language barriers, and lack of transportation and childcare. The development of the intervention system, implementation of the system in these communities, and evaluation of the success of these systems is the responsibility of Project E3 personnel, while allowing state VR agencies to realize the potential benefits of the intervention even with limited allocation of time, personnel, and other resources. Further, Project E3, in developing intervention systems for these communities, also considers the national applicability of the systems with regard to comparable geographic areas containing comparable groups of persons with disabilities. Ultimately, Project E3 is designed for on-the-ground intervention and actionoriented programming to demonstrate the efficacy of different interventions and then train state VR agency personnel on integrating these practices into communities within their states. We look forward to building upon the excellent research contained in this special issue by developing interventions that result in better employment outcomes for persons with disabilities from diverse racial and cultural backgrounds who experience stigma and multiple discrimination associated with a variety of socially devalued characteristics as well as the disadvantages of living in marginalized communities.

\section{Acknowledgments}

Preparation of this editorial is under the Vocational Rehabilitation Technical Assistance Center on Targeted Communities grant (H264F150003) from the Department of Education. However, the ideas, opinions, and conclusions expressed do not necessarily represent the policy of the Department of Education, and endorsement by the Federal Government should not be assumed.

\section{Conflict of interest}

The authors have no conflict of interest to report.

\section{References}

Chan, F., Wong, D. W., Rosenthal, D. A., Kundu, M. M., \& Dutta, A. (2005). Eligibility rates of traditionally underserved individuals with disabilities revisited: A data mining approach. Journal of Applied Rehabilitation Counseling, 36(3), 3-10.

Chiu, C. Y., Chan, F., Sharp, S. E., Dutta, A., Hartman, E., \& Bezyak, J. (2015). Employment as a health promotion intervention for persons with multiple sclerosis. WORK: A Journal of Prevention, Assessment \& Rehabilitation, 52, 749-756.

Erickson, W. Lee, C., \& von Schrader, S. (2014). 2012 Disability Status Report: United States. Ithaca, NY: Cornell University Yang Tan Institute (YTI).

Fryer, R. G., Pager, D., \& Spenkuch, J. L. (2011). Racial disparities in job finding and offered wages. Journal of Law and Economics, 56, 633-689.

Institute on Disability. (2016). Annual disability statistics compendium. Durham, NH: University of New Hampshire.

Neff, W. S. (1986). Work and human behavior (3rd ed.). New York: Aldine de Gruyter. Peterson, P. G. (1996). Will America grow up before it grows old? New York: Random House.

Rogers, N. L., Embree, J. A., Masoudi, N., Huber, J. A, Ford, \& Moore, D. (2011). Consumer perspectives on reasons for unsuccessful VR case closure: An exploratory study. Journal of Vocational Rehabilitation, 34(3), 151-161.

Strauser, D. R. (2014). Introduction to the centrality of work for individuals with disabilities. In D. Strauser (Ed.) Career development, employment, and disability in rehabilitation (pp. 1-10). Springer: New York.

Tansey, T. N. (2008). Training in vocational assessment: Preparing rehabilitation counselors to meet the requirements CORE standards. Rehabilitation Education, 22, 277-286.

Tansey, T. N. \& Smart, J. F. (2004). Training in forensic rehabilitation: Current and potential utility of general graduate level rehabilitation counselor education programs. Journal of Forensic Vocational Analysis, 7, 13-24.

Wehman, P. (2016, May). Critical issues in vocational rehabilitation in the $21^{\text {st }}$ century: 2016-2020. A keynote presented at the annual symposium of the Rehabilitation Research and Training Center on Evidence-Based Practice in Vocational Rehabilitation, Madison, WI.

Yin, M., Shaewitz, D., \& Megra, M. (2014). An uneven playing field: The lack of equal pay for people with disabilities. Washington, D.C: American Institute for Research. 